\title{
Knowledge and Practices of Water Refilling Station Owners and Operators in Providing Safe and Wholesome Drinking Water Supply in One Municipality of Cavite
}

\author{
Monica Alice B. Cope, Samantha Anne S. Gutierrez, Moira Madelle C. Mañalac, \\ Maria Lourdes Ann D.J. Ocampo, Pauline P. Perez and Romeo R. Quizon \\ Department of Environmental and Occupational Health, \\ College of Public Health, University of the Philippines Manila
}

\begin{abstract}
Objectives. This study aimed to a) evaluate the knowledge of water refilling station (WRS) owners and operators regarding the proper techniques and procedures applicable to WRS based on the Certification Course for Water Refilling Station and Plant Operators (CCWRSPO); b) assess compliance to regular physicalchemical and microbiological testing of product water and sanitary permit acquisition and c) determine the quality of product water of selected water refilling stations (WRS) in a municipality in Cavite.
\end{abstract}

Methods. The study included WRS owners and operators who participated in the CCWRSPO from 2005 to 2009. A 50-item objective examination administered by the researchers was used to evaluate the knowledge of the respondents. This was formulated based on the objectives of the CCWRSPO. The compliance to legal requirements for WRS was assessed according to the results of the physical-chemical and microbiological tests (Multiple Tube Fermentation Technique and Pour Plate Method) and the presence of an updated sanitary permit. Results of product water analyses were compared to the 2007 Philippine National Standards for Drinking Water. Water refilling stations that failed to meet at least one of the three legal requirements were considered as "non-compliant".

Results and conclusion. Results showed that $71.8 \%$ of the respondents passed the written examination whereas $28.2 \%$ obtained scores less than $50.0 \%$. Chi-square analysis indicated that there was no significant difference between the knowledge of the trainees in 2005 to 2008 and the trainees in 2009. Similarly, majority (78.9\%) of the WRS included in the study were found to be non-compliant with the provisions of P.D. 856 and the prescribed standards for water quality. The quality of product water served as an important determinant of the compliance of WRS. Although majority of the water samples tested had acceptable microbiological examination results, $16.9 \%$ of the

Corresponding author: Romeo R. Quizon, MSc. Eng'g

Department of Environmental and Occupational Health

College of Public Health

University of the Philippines Manila

625 Pedro Gil St., Ermita, Manila 1000 P.O. Box EA-460 Manila, Philippines

Telephone: $+6325247102 / 5265966$

Fax No: +632 5237745

Email: romeoreyesquizon@yahoo.com samples exceeded the standards for microbiological water quality. Aside from this, the non-compliance of WRS was attributed to the absence of an updated sanitary permit, which was one of the important indicators of product water quality. Chi-square analysis showed that the trainees who have been operating WRS for only a year after the certification course were less compliant as compared to those operating for two to five years.

Key Words: water supply, water safety, sanitation, CCWRSPO, WRS, P.D. 856, PNSDW

\section{Introduction}

\section{Background of the Study}

Many Filipinos consider WRS as trusted sources of drinking water, whether supplementary or alternative to public water supply. ${ }^{1}$ It is therefore important that the quality of water they provide is guaranteed wholesome and safe. Water refilling stations are required by law to operate in accordance to the standards and regulations set to ensure the health and safety of consumers. They are likewise expected to be knowledgeable in the basic techniques and processes applicable to WRS to ensure the proper management, operation, and maintenance of the business.

Chapter II of Presidential Decree 856 (Code on Sanitation of the Philippines) aims to protect public health through the Implementing Rules and Regulations (IRR) for WRS. Water refilling station operators or persons directly involved in the management or supervision of WRS are required to undergo a training course which cover the following topics: ecology, hydrology, microbiology, parasitology, water demand and treatment, sanitary chemistry, plumbing, public health engineering, hazard analysis critical control point and environmental laws. ${ }^{2}$ The said training course should be provided by an institution accredited by the Department of Health. The Department of Environmental and Occupational Health, College of Public Health, University of the Philippines Manila (DEOH, CPH, UPM) has been conducting the CCWRSPO since 2004 and has made the training available to a number of WRS in the country. ${ }^{3}$ 


\section{Statement of the Problem}

This study aimed to determine whether the certification course offered by $\mathrm{DEOH}$ is related to the compliance of selected WRS to legal requirements, the quality of product water and the knowledge of selected respondents from one of the municipalities of Cavite. More specifically, the study aimed to answer the following:

1. Will the knowledge of trainees regarding the principles, techniques and processes applicable to WRS differ relative to the number of years of operation after certification?

2. Will the compliance (in terms of operation and maintenance) of WRS owners and operators to the Code on Sanitation of the Philippines differ relative to the number of years after the certification course?

3. Is the quality of water delivered by WRS safe and wholesome as determined by the results of physical, chemical and microbiological analyses?

\section{Objectives of the Study}

\section{General Objective}

To evaluate the knowledge and practices of WRS owners and operators in one municipality in Cavite with respect to the provision of safe and wholesome drinking water.

\section{Specific Objectives}

1. To evaluate the knowledge of WRS owners and operators (stratified according to year of training) based on the following objectives of the CCWRSPO:

a. Adherence to laws and policies pertinent to the maintenance and provision of safe drinking water;

b. Periodic submission of properly collected water sample for physical-chemical and microbiological examination to $\mathrm{DOH}$-accredited water testing laboratories;

c. Promotion of water sanitation and safety;

d. Awareness on the effects of water quality on health; and

e. Technical management of WRS

2. To evaluate the compliance of WRS owners and operators (stratified according to year of training) based on the following provisions of the Code on Sanitation of the Philippines:

a. Sanitary Permit Inspection

b. Physical-Chemical Analysis of Water

c. Microbiological Analysis of Water

3. To describe the quality of product water in WRS using physical-chemical and microbiological parameters.

\section{Scope and Delimitation of the Study}

The respondents of the study included owners and/or operators of WRS in a municipality in Cavite who completed the CCWRSPO conducted by DEOH between 2005 and 2009. Each respondent has worked in the same WRS from the end of the training up to the beginning of the study. Furthermore, only WRS listed in the database of DEOH were considered. The study did not include an assessment of the efficiency of water treatment equipment and the delivery of product water, which are included in sanitation and safety practices of the WRS. Thus, an assessment of the total performance of the retail system was not obtained. Radiological quality of drinking water especially for water refilling stations was not included because it is not identified as one of priority drinking water quality parameters for monitoring by $\mathrm{DOH}$. This will only be included in the priority list if there is fall-out or contamination from suspected sources of radiological impurities. This should be identified by DOH or Philippine Nuclear Research Institute.

\section{Significance of the Study}

Contaminated water poses great risks to public health including the spread of water-borne diseases and exposure to toxic chemicals. Most of the time, the levels of contaminants are not sufficient to cause acute effects, such as dizziness, nausea and diarrhea. Contaminants are more likely to cause chronic effects, such as cancer, liver problems, kidney problems, or reproductive difficulties, which occur after repeated exposures to small amounts of a particular chemical. ${ }^{4}$ All these health problems stem from unsanitary or contaminated water sources. Considering the adverse effects of ingesting contaminated water, it is imperative that sources of drinking water are safe and of good quality.

\section{Methods}

\section{Study Design}

A cross-sectional study design was used to assess the knowledge and compliance of owners and operators to the laws, principles, techniques and processes applicable to WRS with respect to year of training.

\section{Operational Definition of Variables}

\section{Knowledge on the Basic Principles, Techniques and} Processes Applicable to WRS

The knowledge of WRS owners and operators on the basic techniques and procedures applicable to WRS was assessed based on the five objectives of the certification course.

\section{Sanitary Permit}

The researchers inspected the sanitary permits of the WRS selected for this study. Sanitary permits were classified as updated, expired or absent. Only updated sanitary permits were accepted as a measure of compliance. 


\section{Physical-Chemical Quality of Water}

Sample product water was collected by the researchers and tested for physical-chemical quality at the DEOH laboratory. The physical-chemical analysis of water sample, which was based on the Philippine National Standard for Drinking Water 2007 (PNSDW), ${ }^{5}$ involved the determination of the levels of 11 parameters. The physical parameters included color, odor and turbidity whereas the chemical parameters tested were $\mathrm{pH}$, alkalinity, calcium, chloride, iron, sulfate, total dissolved solids and hardness. The results were considered acceptable if the values obtained were within the acceptable limits set by the PNSDW. ${ }^{6}$

\section{Microbiological Quality of Water}

Product water samples were collected by the researchers and tested for microbiological water quality at the Department of Medical Microbiology (DMM) laboratory of the CPH, UPM. The analysis of water samples involved two procedures: Multiple Tube Fermentation Technique (MTFT)-Total Coliform Test and Pour-Plate Method. When tested using the MTFT, the value for total coliforms must not exceed 1.1 MPN/100 mL. A limit of less than 500 colony forming units (CFU) was set for the Pour-Plate Method. ${ }^{7}$

\section{Compliance with the Provisions of the Code on Sanitation of the Philippines}

Water refilling stations were considered "compliant" with the Code on Sanitation of the Philippines (P.D. 856) if they meet the following requirements: presence of an updated sanitary permit and compliance with the PNSDW for product water quality. ${ }^{8}$ Failure of the WRS to meet at least one of these requirements implied that there is/are unacceptable practice/s in the operation and management of the WRS. This is equivalent to non-compliance with the provisions of the P.D. 856.

\section{Study Area}

The study included selected WRS in one of the most populous and urbanized municipalities in the province of Cavite. As of the first quarter of 2010, there were 246 WRS listed by the municipal sanitary inspector. Of this number, 197 WRS were manned by employees who underwent the CCWRSPO training. Out of 197 respondents, there were 171 owners and/or operators who underwent the training course between 2005 and 2009. ${ }^{9}$ Currently, there are 126 operating WRS with such employees.

\section{Study Population}

\section{Sampling Design}

Stratified sampling design was used in determining the sample size. The members of the target population were grouped according to the year when they underwent training and the number of years of operation after the CCWRSPO. The first group was composed of respondents who underwent training in the past three years or more (from 2005 to 2007) and with three to five years of operation after the training; the second group was composed of respondents who were trained in 2008 with two years of operation after certification; the third group was composed of respondents who were trained in 2009 with one year of operation after the CCWRSPO. After grouping the trainees, the sample size was estimated by computing for the single population proportion. The sample size estimates were adjusted using finite population correction for proportions. Random sampling was used to select the respondents from each group.

\section{Sample Size}

The tools used for sample size determination are shown below. The summary of sample size data per stratum is shown in Table 1.

a. Single Population Proportion (necessary sample size) $n_{0}=\left[\left(t_{1-\alpha / 2}\right)^{2}\right.$ p $x$ q $\left.q\right] / d^{2}$

b. Finite Population Correction for Proportions (reduced sample size)

$n_{\text {Group }}=n_{0} /\left[1+\left(n_{0}-1 / N\right)\right]$

where:

$\mathrm{x}$ = group number

$\mathrm{p}=$ sample proportion of expected exam passers

$\mathrm{q}=1-\mathrm{p}$

$\mathrm{z}=$ normal deviate (two-tailed)

$\mathrm{d}=$ precision

$\mathrm{n}_{\mathrm{o}}=$ estimated sample size per stratum

$\mathrm{n}=$ adjusted sample size per stratum

\section{Data Processing and Analysis}

1. Knowledge on the Basic Principles, Techniques and Processes Applicable to Water Refilling Stations

To evaluate the knowledge of WRS owners and operators stratified according to year of training, the Chi-

Table 1. Summary of Sample Size Data per Stratum

\begin{tabular}{|c|c|c|c|c|c|c|c|c|c|}
\hline Group & Year of Training & Years of Operation After the Certification & $\mathbf{N}$ & d & $\mathbf{p}$ & $q$ & $\begin{array}{l}\text { t-value } \\
(\alpha=0.1)\end{array}$ & $\mathrm{n}_{\mathrm{o}}$ & $n_{\text {Grp }}$ \\
\hline 1 & $2005-2007$ & $3-5$ & 18 & 0.1 & 0.7 & 0.3 & 1.64 & 57 & 14 \\
\hline 2 & 2008 & 2 & 49 & 0.1 & 0.7 & 0.3 & 1.64 & 57 & 27 \\
\hline 3 & 2009 & 1 & 59 & 0.1 & 0.7 & 0.3 & 1.64 & 57 & 30 \\
\hline Total & & & 126 & & & & & & 71 \\
\hline
\end{tabular}


square Test of Homogeneity was applied using Epi Info version 3.5.1. The statistical software was also used to determine if the proportion of participants who qualified the exam from each group was similar. This statistical measure aimed to determine whether three or more populations have the same distribution with respect to a single characteristic of interest, referred to as a categorical variable. The tool is applicable when simple random sampling is utilized for data collection and the expected count for each of the components of the contingency table is $\geq 1$ and no more than $20 \%$ of the values obtained is $<5$.

The null hypothesis stated that all groups have the same proportion of exam passers. If the chi-square value computed is greater than or equal to the chi-square distribution value for a certain degree of freedom and significance level, then the null hypothesis is rejected. The confidence interval was set at $90 \%$, with a level of significance equal to 0.10 .

The contingency table showed the observed frequencies for all possible combinations of the different categories found under each of the two variables. The rows of the table represent the three groups of trainees categorized according to years of operation after certification while the columns represent the passers and non-passers. The passing score was at least $50 \%$, or at least 25 correct answers out of 50 .

In assessing which areas of the certification course the respondents were least knowledgeable in, the exam was divided into five different parts that correspond to the specific objectives of the course. All parts of the exam were assumed to have equal weights, thus scores for each part were analyzed separately. A passing grade of $50 \%$ was also applied to each part of the exam.

\section{Compliance with the Provisions of Presidential Decree 856 (Code on Sanitation of the Philippines)}

In evaluating the compliance of the trainees with the provisions of P.D. 856, three indicators were used: presence of updated sanitary permits and acceptable results of the physical-chemical analysis and microbiological analysis of product water samples. With respect to the first indicator, only updated sanitary permits were considered as indicators of compliance. For the second and third indicators, the analyses for physical-chemical and microbiological parameters confirmed whether the trainees conform to standard water treatment procedures. Failure to meet at least one of the limits of the PNSDW indicated noncompliance to the provisions of P.D. 856.

The Chi-square Test of Homogeneity was used to analyze the results. The null hypothesis stated that all the groups have the same proportion of compliance. If the chisquare value computed was greater than or equal to the chisquare distribution value for a certain degree of freedom and significance level, then the null hypothesis is rejected. The confidence interval was set at $90 \%$, with a level of significance equal to 0.10 .

\section{Results and Discussion}

Knowledge on the Basic Principles, Techniques and Processes Applicable to Water Refilling Stations

Table 2 shows that majority or $72.0 \%$ of the respondents obtained passing scores in the written examination. The proportions of exam passers in groups 1, 2 and 3 were $50.0 \%$, $81.5 \%$, and $73.3 \%$, respectively. It was observed that the passing rates decreased relative to the length of operation after certification. The high passing rate among respondents who completed the certification course in 2009 is attributed to better recall of the principles and concepts that were presented during the certification course. However, to validate the inference that the knowledge of the respondents is associated with the length of operation after certification, the proportion of passers from each group was compared to check if there was a significant difference between them. Chi-square analysis of the data from Table 5 showed that the knowledge level of respondents were equal. In order to determine which aspects of the CCWRSPO the participants are least knowledgeable in, the proportion of passers in each part of the exam were computed. The corresponding passing rates were: $66.2 \%$ for part II, $77.5 \%$ for parts I, IV and V and $69.0 \%$ for part III (Table 3). Low passing rates were noted in the second and third part of the exam thus indicating that the respondents are least knowledgeable in: a) the periodic submission of properly collected water samples for physicalchemical and microbiological examination to $\mathrm{DOH}-$ accredited laboratories, and b) promotion of water sanitation and safety.

Table 4 is a cross-tabulation of the groups of trainees and exam passers and non-passers after merging Groups 1 and 2. It can be seen that the first group (respondents trained between 2005 and 2008) has a $70.7 \%$ proportion of passers as

Table 2. Number and Percentage of Exam Passers and Non- Passers among Groups of Trainees

\begin{tabular}{|c|c|c|c|c|c|c|c|c|}
\hline \multirow[b]{3}{*}{ Group } & \multirow[b]{3}{*}{ Year of Training } & \multirow[b]{3}{*}{ Years of Operation After Certification } & \multicolumn{4}{|c|}{ Exam Status } & \multirow{2}{*}{\multicolumn{2}{|c|}{ Total }} \\
\hline & & & \multicolumn{2}{|c|}{ Passer } & \multicolumn{2}{|c|}{ Non- Passer } & & \\
\hline & & & No. & $\%$ & No. & $\%$ & No. & $\%$ \\
\hline 1 & $2005-2007$ & $3-5$ & 7 & 50 & 7 & 50 & 14 & 100 \\
\hline 2 & 2008 & 2 & 22 & 81.5 & 5 & 18.5 & 27 & 100 \\
\hline 3 & 2009 & 1 & 22 & 73.3 & 8 & 26.7 & 30 & 100 \\
\hline Total & & & 51 & 71.8 & 20 & 28.2 & 71 & 100 \\
\hline
\end{tabular}


compared to the $73.3 \%$ passing rate in Group 2 (trainees from 2009). In addition to these findings, most of the WRS included in this study failed to present updated sanitary permits, which, according to law, is an important indicator of the quality and safety of the product water.

Table 3. Number and Percentage of Exam Passers and NonPassers among Trainees Based on Partial Score

\begin{tabular}{llcccc}
\hline \multirow{2}{*}{\multicolumn{1}{c}{ Exam Part }} & \multicolumn{4}{c}{ Exam Status } \\
\cline { 3 - 6 } & & \multicolumn{3}{c}{ Passers } & \multicolumn{2}{c}{ Non- Passers } \\
\cline { 3 - 6 } & & No. & \% & No. & \% \\
\hline Part I: & Laws and Policies & 55 & 77.5 & 16 & 22.5 \\
Part II: & Water Sampling & 47 & 66.2 & 24 & 33.8 \\
Part III: & Water Sanitation and Safety & 49 & 69 & 22 & 31 \\
Part IV: & Water Quality & 55 & 77.5 & 16 & 22.5 \\
Part V: & Management & 55 & 77.5 & 16 & 22.5 \\
\hline
\end{tabular}

\section{Compliance with the Provisions of the Code on Sanitation of the Philippines}

Table 5 shows compliance rates among the three groups of trainees. Twenty-one percent of the respondents were found compliant with the provisions of P.D. 856. The computed rates were $42.9 \%, 22.2 \%$ and $10.0 \%$ for Groups 1,2 and 3 , respectively.

Results of the Heterotrophic Plate Count (HPC) and Total Coliform Tests for product water samples are shown in Tables 6 and 7. Acceptable HPC results were noted in $85.7 \%$ of WRS belonging to Group 1, 93.3\% in Group 3 and $100.0 \%$ in Group 2. However, the total coliform tests showed significantly lower percentages of WRS with acceptable results: $83.3 \%$ for Group 3, 85.7\% for Group 1 and $92.6 \%$ for Group 2. Tables 8 and 9 summarize the proportion of WRS with acceptable and unacceptable water quality test results. Table 8 presents both the heterotrophic plate count and total coliform test results. Out of 71 samples, $83.0 \%$ have acceptable microbiological quality whereas all water samples have acceptable physical-chemical quality (Table 9).

Table 11 is a cross-tabulation of trainees by group and compliance rate after merging Groups 1 and 2. The results of the single table analysis shown in Table 5 indicate that the chi-square test is not valid because there were values less than five. Thus, adjacent categories (Groups 1 and 2) were

Table 4. Distribution of Trainees by Group and Exam Results after Merging Groups 1 and 2

\begin{tabular}{|c|c|c|c|c|c|c|c|c|}
\hline \multirow{3}{*}{ Group } & \multirow{3}{*}{ Year of Training } & \multirow{3}{*}{ Years of Operation After Certification } & \multicolumn{4}{|c|}{ Exam Result } & \multirow{2}{*}{\multicolumn{2}{|c|}{ Total }} \\
\hline & & & \multicolumn{2}{|c|}{ Passers } & \multicolumn{2}{|c|}{ Non- Passers } & & \\
\hline & & & No. & $\%$ & No. & $\%$ & No. & $\%$ \\
\hline $1-2$ & 2005- 2008 & $2-5$ & 29 & 70.7 & 12 & 29.3 & 41 & 100 \\
\hline 3 & 2009 & 1 & 22 & 73.3 & 8 & 26.7 & 30 & 100 \\
\hline Total & & & 51 & 71.8 & 20 & 28.2 & & 100 \\
\hline
\end{tabular}

Table 5. Number and Percentage of Compliant and Non-Compliant Trainees among Groups

\begin{tabular}{|c|c|c|c|c|c|c|c|c|}
\hline \multirow{2}{*}{ Group } & \multirow{2}{*}{ Year of Training } & \multirow{2}{*}{ Years of Operation After Certification } & \multicolumn{2}{|c|}{ Compliant } & \multicolumn{2}{|c|}{ Non- Compliant } & \multicolumn{2}{|c|}{ Total } \\
\hline & & & No. & $\%$ & No. & $\%$ & No. & $\%$ \\
\hline 1 & $2005-2007$ & $3-5$ & 6 & 42.9 & 8 & 57.1 & 14 & 100 \\
\hline 2 & 2008 & 2 & 6 & 22.2 & 21 & 77.8 & 27 & 100 \\
\hline 3 & 2009 & 1 & 3 & 10 & 27 & 90 & 30 & 100 \\
\hline Total & & & 15 & 21.1 & 56 & 78.9 & 71 & 100 \\
\hline
\end{tabular}

Table 6. Number and Percentage of Heterotrophic Plate Count Results among Groups of Trainees

\begin{tabular}{|c|c|c|c|c|c|c|}
\hline \multirow{3}{*}{ Group } & \multirow{3}{*}{ Year of Training } & \multirow{3}{*}{ Years of Operation After Certification } & \multicolumn{4}{|c|}{ Heterotrophic Plate Count Results } \\
\hline & & & \multicolumn{2}{|c|}{ Acceptable } & \multicolumn{2}{|c|}{ Unacceptable } \\
\hline & & & No. & $\%$ & No. & $\%$ \\
\hline 1 & $2005-2007$ & $3-5$ & 12 & 85.7 & 2 & 14.3 \\
\hline 2 & 2008 & 2 & 27 & 100 & 0 & 0 \\
\hline 3 & 2009 & 1 & 28 & 93.3 & 2 & 6.7 \\
\hline Total & & & 67 & 94.4 & 4 & 5.6 \\
\hline
\end{tabular}

Table 7. Number and Percentage of Total Coliform Test Results among Groups of Trainees

\begin{tabular}{|c|c|c|c|c|c|c|}
\hline \multirow{3}{*}{ Group } & \multirow{3}{*}{ Year of Training } & \multirow{3}{*}{ Years of Operation After Certification } & \multicolumn{4}{|c|}{ Most Probable Number Results } \\
\hline & & & \multicolumn{2}{|c|}{ Acceptable } & \multicolumn{2}{|c|}{ Unacceptable } \\
\hline & & & No. & $\%$ & No. & $\%$ \\
\hline 1 & $2005-2007$ & $3-5$ & 12 & 85.72 & 2 & 14.28 \\
\hline 2 & 2008 & 2 & 25 & 92.59 & 2 & 7.41 \\
\hline 3 & 2009 & 1 & 25 & 83.33 & 5 & 16.67 \\
\hline Total & & & 62 & 87.32 & 9 & 12.68 \\
\hline
\end{tabular}


merged to increase the expected frequencies. As shown in Table 11, the compliance levels in the two groups of trainees differed significantly. Non-compliance rates were greater in Group 3 as compared to the combined percentages of Groups 1 and 2. This could be explained by the following: a) applications for sanitary permits are still being processed at the time of study; b) financial constraints; and c) lack of knowledge regarding the legal requirements for WRS. It was shown that the trainees belonging to Group 1, who underwent training between 2005 and 2008, have a 29.3\% compliance rate as compared to $10.0 \%$ of those in Group 2, who were trainees from 2009. In summary, majority of the WRS included in this study were found to be non-compliant to the provisions of the Code on Sanitation. It can be noted that compliance rates are lower among those who have recently completed the certification course.

\section{A. Microbiological Analysis Results}

The results obtained were compared to the limits specified in the PNSDW. Failure to meet the prescribed standards indicated inefficiency in the water treatment process and/or post-contamination of product water. Results of microbiological analysis did not greatly affect noncompliance rates as compared to sanitary permit acquisition. As shown in Tables 7 and 8, majority of the product water samples tested have values within the acceptable limits set by the PNSDW. Although majority of the samples tested have acceptable results, approximately $16.9 \%$ of the samples tested exceeded bacteriological quality standards. Considering that the presence of bacteria in drinking water poses threat to public health, further testing is warranted (e.g., test for fecal coliforms).

Table 8. Number and Percentage of Acceptable and Unacceptable Results of Microbiological Water Quality Analysis among Groups of Trainees

\begin{tabular}{|c|c|c|c|c|c|c|}
\hline \multirow{3}{*}{ Group } & \multirow{3}{*}{ Year of Training } & \multirow{3}{*}{ Years of Operation After Certification } & \multicolumn{4}{|c|}{ Microbiological Water Quality Results } \\
\hline & & & \multicolumn{2}{|c|}{ Acceptable } & \multicolumn{2}{|c|}{ Unacceptable } \\
\hline & & & No. & $\%$ & No. & $\%$ \\
\hline 1 & 2005-2007 & 5-Mar & 10 & 71.4 & 4 & 28.6 \\
\hline 2 & 2008 & 2 & 25 & 92.6 & 2 & 7.4 \\
\hline 3 & 2009 & 1 & 24 & 80 & 6 & 20 \\
\hline Total & & & 59 & 83.1 & 12 & 16.9 \\
\hline
\end{tabular}

Table 9. Number and Percentage of Acceptable and Unacceptable Results of Physical- Chemical Water Quality Analysis among Groups of Trainees

\begin{tabular}{|c|c|c|c|c|c|c|}
\hline \multirow{3}{*}{ Group } & \multirow{3}{*}{ Year of Training } & \multirow{3}{*}{ Years of Operation After Certification } & \multicolumn{4}{|c|}{ Physical- Chemical Water Quality Results } \\
\hline & & & \multicolumn{2}{|c|}{ Acceptable } & \multicolumn{2}{|c|}{ Unacceptable } \\
\hline & & & No. & $\%$ & No. & $\%$ \\
\hline 1 & $2005-2007$ & $3-5$ & 14 & 100 & 0 & 0 \\
\hline 2 & 2008 & 2 & 27 & 100 & 0 & 0 \\
\hline 3 & 2009 & 1 & 30 & 100 & 0 & 0 \\
\hline Total & & & 71 & 100 & 0 & 0 \\
\hline
\end{tabular}

Table 10. Number and Percentage of Sanitary Permit Status among Groups of Trainees

\begin{tabular}{|c|c|c|c|c|c|c|}
\hline \multirow{3}{*}{ Group } & \multirow{3}{*}{ Year of Training } & \multirow{3}{*}{ Years of Operation After Certification } & \multicolumn{4}{|c|}{ Sanitary Permit Status } \\
\hline & & & \multicolumn{2}{|c|}{ Updated } & \multicolumn{2}{|c|}{ Absent } \\
\hline & & & No. & $\%$ & No. & $\%$ \\
\hline 1 & $2005-2007$ & $3-5$ & 7 & 50 & 7 & 50 \\
\hline 2 & 2008 & 2 & 6 & 22.2 & 21 & 77.8 \\
\hline 3 & 2009 & 1 & 3 & 10 & 27 & 90 \\
\hline Total & & & 16 & 22.5 & 55 & 77.5 \\
\hline
\end{tabular}

Table 11. Distribution of Trainees by Group and Compliance after Merging Groups 1 and 2

\begin{tabular}{|c|c|c|c|c|c|c|c|c|}
\hline \multirow{2}{*}{ Group } & \multirow{2}{*}{ Year of Training } & \multirow{2}{*}{ Years of Operation After Certification } & \multicolumn{2}{|c|}{ Compliant } & \multicolumn{2}{|c|}{ Non-Compliant } & \multicolumn{2}{|c|}{ Total } \\
\hline & & & No. & $\%$ & No. & $\%$ & No. & $\%$ \\
\hline $1-2$ & 2005- 2008 & $3-5$ & 12 & 29.3 & 29 & 70.7 & 41 & 100 \\
\hline 3 & 2009 & 1 & 3 & 10 & 27 & 90 & 30 & 100 \\
\hline Total & & & 15 & 21.1 & 56 & 78.9 & 71 & 100 \\
\hline
\end{tabular}




\section{A. Physical-Chemical Analysis Results}

The result of physical-chemical analysis of product water was one of the important determinants of compliance to regulations and standards for WRS. The values obtained were useful in determining the quality of product water.

1. Physical Parameters

a. Color

The color of drinking water does not have direct effects on health but it is a useful indicator of water contamination. The quality guideline for color is aesthetic, thereby determining its acceptability for drinking and domestic use. Ideally, drinking water should be clear and colorless, specifically measured as having less than 5.0 true color units (TCU). ${ }^{10}$ All 71 WRSs passed the PNSDW standard for the color of water.

b. Odor

Odor is regarded as a quality factor influencing the acceptability of drinking water. It is used as an indicator of organic and inorganic chemical contamination, including those from industrial waste discharges and natural sources such as decomposition of vegetable matter or from associated microbial activity. All 71 WRS passed.

c. Turbidity

Turbidity is the measure of the amount of light scattered and absorbed by water due to suspended particles. ${ }^{11}$ The acceptable turbidity level for potable water is $<5$ Nephelometric Turbidity Unit (NTU). ${ }^{12}$ All 71 WRSs passed.

2. Chemical Parameters

a. $\mathrm{pH}$

Based on the $2007 \mathrm{PNSDW}$, the overall $\mathrm{pH}$ range of drinking water is generally between 6.5 and 8.5. Standard $\mathrm{pH}$ values were set as these may affect the taste of drinking water. Samples with $\mathrm{pH}$ lower than 4.0 will produce sour taste whereas those with values above 8.5 may taste bitter. All 71 WRS passed.

b. Calcium

Calcium, which is naturally present in water, comes from the decomposition of calcium aluminosilicates, and at higher concentrations from dissolution of limestones, magnesium, magnesite, gypsum and other minerals. ${ }^{13}$ All 71 WRSs passed.

c. Chloride

Chloride is one of the major inorganic anions in water. There is no evidence suggesting that chloride is a human health hazard. For this reason, the limit for chloride in drinking water is set at $250 \mathrm{mg} / \mathrm{L} .{ }^{14}$ All 71 WRSs passed. d. Iron

Iron is frequently found in water due to the presence of large deposits in the earth's surface. It can also be introduced into drinking water from iron pipes in the water distribution system. Iron is not an acute health hazard. However, it is counted as a secondary or aesthetic contaminant, which results in unpalatability or undesirability of taste or odor. ${ }^{15,16}$ All 71 WRSs passed.

e. Sulfate

The major physiological effects resulting from the ingestion of large quantities of sulfate are catharsis, dehydration, and gastrointestinal irritation. Water containing magnesium sulfate at levels above $600 \mathrm{mg} / \mathrm{L}$ has a purgative effect in humans. ${ }^{17}$ Hence, the acceptable limit for sulfate is $\leq 250.0 \mathrm{mg} / \mathrm{L} \mathrm{SO}_{4}$. All 71 WRSs passed.

f. Total Dissolved Solids (TDS)

Principally, inorganic salts are considered as dissolved solids in water, which include: calcium, chloride, iron, and sulfate. These inorganic salts do not contribute nor impose any risk to public health. However, excessive levels of total dissolved solids may cause unpalatability of water. ${ }^{18}$ The acceptable limit for TDS is 500.0 TDS. ${ }^{19}$ All 71 WRSs have $\leq 500.0$ TDS.

g. Total Hardness

Calcium and magnesium contribute to water hardness. These elements may be intentionally supplemented to drinking water as part of treatment through the process of calcium hydroxide or filtration through different compounds counteracting acidity such as $\mathrm{CaCO}_{3}$, $\mathrm{MgCO}_{3}$, and $\mathrm{MgO}^{20}$ For total hardness, the acceptable limit is $\leq 300.0 \mathrm{mg} / \mathrm{L}$. As shown in Table 10, WRS passed the parameters for physical and chemical analysis.

\section{B. Sanitary Permit}

Sanitary permit acquisition served as one of the measures of compliance for selected WRS in Cavite. Its presence in any establishment is instituted by law as stated in Section 4 of the Supplemental Implementing Rules and Regulation of Chapter II- "Water Supply" of the Code on Sanitation of the Philippines. As shown in Table 11, the lack of updated sanitary permits significantly contributed to noncompliance among the trainees. Furthermore, trainees who have recently completed the certification course were found to be more non-compliant with respect to this requirement. Water refilling station owners and operators who attended the certification course three to five years ago presented more updated sanitary permits than those who were trained one to two years ago. Reasons for participants' failure to apply for sanitary permits included financial constraints and 
lack of knowledge on the importance of the sanitary permit acquisition.

Evaluation of the knowledge of respondents on the principles, techniques and processes applicable to WRS revealed a higher percentage of passers. However, chisquare analysis showed that there is no significance difference between the knowledge of the trainees from the year 2005 to 2007, trainees from the year 2008, and trainees from the year 2009. Furthermore, respondents were found to be least knowledgeable on water sampling and water sanitation and safety.

Compliance with the provisions of the Code on Sanitation was determined using three parameters: microbiological testing, physical-chemical testing, and presence of a sanitary permit. Trainees from the year of 2009 showed the highest percentage of non-compliance. The compliance rates of the trainees from the year 2005 to 2008 significantly differs from that of the trainees from the year 2008 and 2009.

\section{Recommendations}

\section{A. Future Studies}

Based on the findings of this study, the researchers recommend the following:

1. The sample size should be increased to allow for a more extensive analysis. Increasing the sample size will also increase the accuracy of the results because there are more data available. In addition, if more data are gathered, more relationships may be inferred from the results obtained.

2. With respect to the clustering of WRS according to the length of operation after the certification course, an interval of five years should be observed to determine the effect of time on the knowledge and compliance of the operators to the rules and regulations for WRS. An interval of about 5 years establishes the premise that the trainees have had sufficient time to practice and apply what they have learned during the certification course.

3. In determining the compliance of the owners and operators to regulations, additional criteria should be used and a better pass or fail system be designed. Fecal Coliform Tests should be performed as it is important to public health.

\section{B. Public Health Concerns and Interventions}

It is highly recommended that the findings of the study serve as bases for policy action on the part of the authorities to ensure continued supply of safe drinking water to the public. Concerned authorities should present the information to all the water stations under their jurisdiction and make it known that there are sanctions for violators to the regulations. From this action, it is suggested that the authorities will impose a stricter implementation of the rules and regulations to ensure that all stations comply with the policies and assure the safety of the public. Presently, the municipality concerned has only one sanitary inspector when ideally there should be one sanitary inspector to serve 20,000 people for quality service. The lone sanitary inspector catering to an estimated 400,000 people does not equate with quality service. This could be the reason in the delay of the processing of the sanitary permits of some of the water stations making them fail in the said parameter. It is recommended that this matter be given attention by concerned authorities. More sanitary inspectors should be appointed to cater to the people of the concerned municipality.

\section{CCWRSPO: Basis for Action}

Low compliance rates were noted among respondents included in the study. Although there were few stations that failed in the microbiological tests, a greater number of respondents failed to present an updated sanitary permit upon inspection of the researchers. As such, the absence of an updated sanitary permit became the main reason why majority of the WRS were categorized as non-compliant. The CCWRSPO should therefore emphasize the importance of updating the sanitary permits annually as this is required by law. Consequently, this will help in strengthening the confidence of the public in buying water from the stations.

\section{References}

1. Magtibay BB. Water-refilling station: an alternative source of drinking water supply in the Philippines [Online]. 2001 [cited 2010 Oct]. Available from http://www.mixph.com/2006/10/a-study-on-waterrefilling-station.html.

2. Department of Health (DOH). Supplemental implementing rules and regulations of chapter II - "water supply," of the code on sanitation of the Philippines. Section 9.5.1. 1999. pp. 27.

3. Memorandum of understanding between the DOH and the UP-CPH on the implementation of the certification course for water refilling station and plant operators. 2004

4. World Health Organization (WHO). Guidelines for drinking-water quality, 3ed. Geneva. 2004.

5. DOH. Philippine national standards for drinking water (Administrative Order No. 2007-2012). Sta. Cruz, Manila. 2007. pp 21-26.

6. DOH. Philippine national standards for drinking water (Administrative Order No. 2007-2012). Sta. Cruz, Manila. 2007. pp 7-8.

7. DOH. Philippine national standards for drinking water (Administrative Order No. 2007-2012). Sta. Cruz, Manila. 2007. pp. 12-15.

8. DOH. Supplemental implementing rules and regulations of chapter II "water supply," of the code on sanitation of the Philippines. 1999.

9. Municipal Health Office (MHO), Bacoor, Cavite. Health and environmental sanitation records. 2005-2009.

10. DOH. Philippine national standards for drinking water (Administrative Order No. 2007-2012). Sta. Cruz, Manila. 2007. pp. 24.

11. APEC. Turbidity of drinking water [Online]. [cited 2010 Oct]. Available from http://www.freedrinkingwater.com/water-education2/812turbidity-water.htm. 
12. DOH. Philippine national standards for drinking water (Administrative Order No. 2007-2012). Sta. Cruz, Manila. 2007.

13. Kozisek F. Health significance of drinking water calcium and magnesium [Online]. 2003 [cited 2010 Oct]. Available from http://www.midasspringwater.com/typed\%20documents/HealthSignific ance.pdf.

14. The drop on water: Chloride [Online]. [cited 2010 Oct]. Available from http://www.gov.ns.ca/nse/water/docs/droponwaterFAQ_Chloride.pdf.

15. Illinois Department of Public Health. Iron in Drinking Water [Online]. $1999 \quad$ [cited $2010 \quad$ Oct]. Available from http://www.idph.state.il.us/envhealth/factsheets/ironFS.htm.

16. Environmental Protection Agency. Iron [Online]. 2010 [cited 2010 Oct]. Available from http://www.epa.gov/nrmrl/wswrd/cr/corr_res_iron.html.

17. Dvorak B, Skipton S, Woldt W. Drinking water: sulfur (sulfate and hydrogen sulfide) [Online]. 2010 [cited 2010 Oct]. Available from NebGuide: http://www.ianrpubs.unl.edu/epublic/live/g1275/build/ g1275.pdf.

18. WHO. Total dissolved solids in drinking water- background document for development of WHO guidelines for drinking water quality [Online]. 2003 [cited 2010 Oct]. Available from http://www.who.int/ water_sanitation_health/dwq/chemicals/tds.pdf.

19. Department of Health (DOH). Philippine national standards for drinking water (Administrative Order No. 2007-2012). Sta. Cruz, Manila. 2007. pp. 25.

20. Hardness in drinking water [Online]. 2004 [cited 2010 Oct]. Available from http://www.watersystemscouncil.org/VAiWebDocs/WSCDocs/ 1683274HARDNESS.PDF.

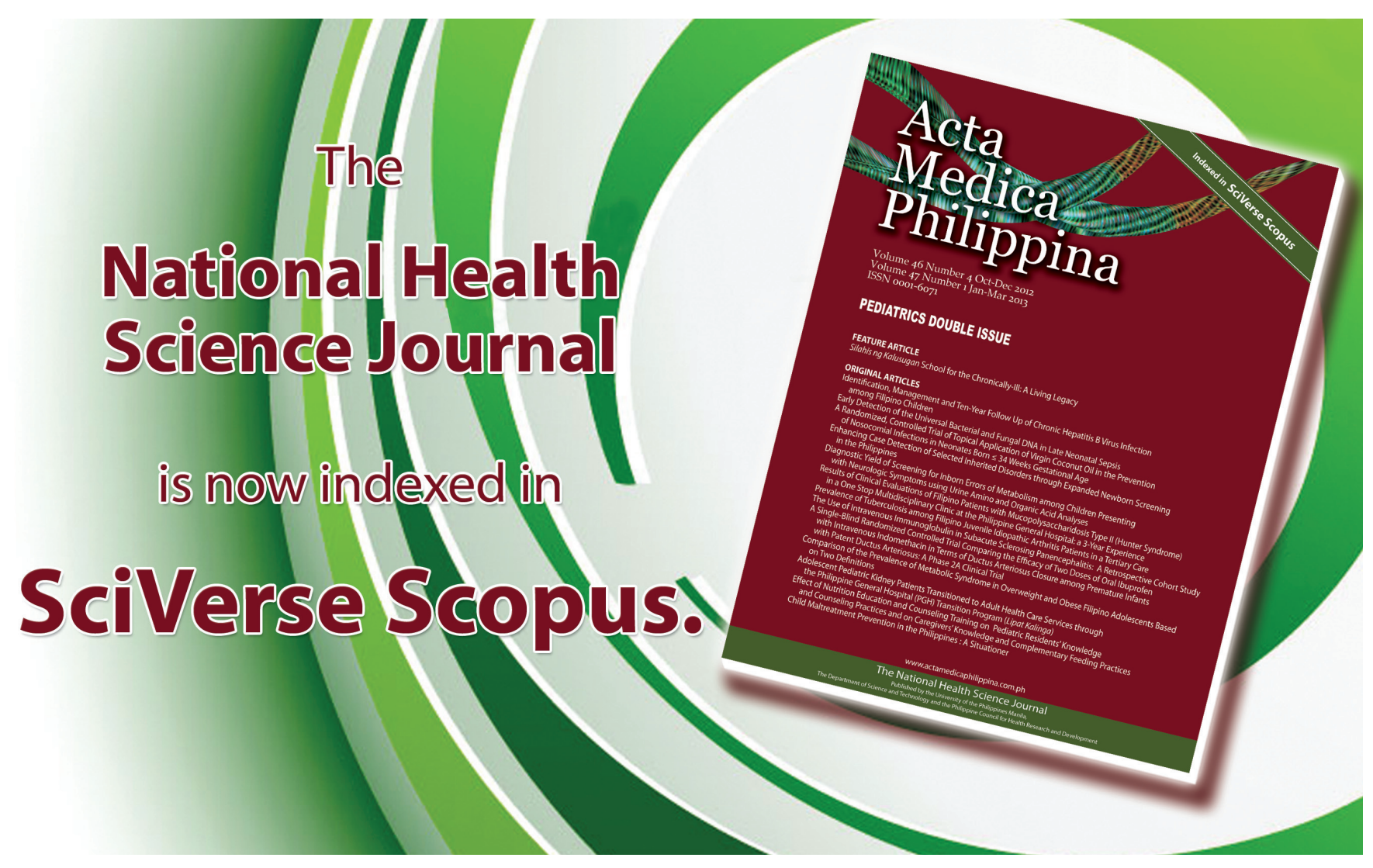

